\title{
Oxidant production from source-oriented particulate matter - Part 1: Oxidative potential using the dithiothreitol (DTT) assay
}

\author{
J. G. Charrier ${ }^{1}$, N. K. Richards-Henderson ${ }^{1}$, K. J. Bein ${ }^{2,3}$, A. S. McFall ${ }^{1}$, A. S. Wexler ${ }^{1,2,4}$, and C. Anastasio ${ }^{1}$ \\ ${ }^{1}$ Department of Land, Air and Water Resources, University of California, Davis, CA 95616, USA \\ ${ }^{2}$ Air Quality Research Center, University of California, Davis, CA 95616, USA \\ ${ }^{3}$ Center for Health and the Environment, University of California, Davis, CA 95616, USA \\ ${ }^{4}$ Department of Mechanical and Aeronautical Engineering, University of California, Davis, CA 95616, USA
}

Correspondence to: C. Anastasio (canastasio@ucdavis.edu)

Received: 5 September 2014 - Published in Atmos. Chem. Phys. Discuss.: 18 September 2014

Revised: 10 February 2015 - Accepted: 10 February 2015 - Published: 4 March 2015

\begin{abstract}
Recent epidemiological evidence supports the hypothesis that health effects from inhalation of ambient particulate matter (PM) are governed by more than just the mass of PM inhaled. Both specific chemical components and sources have been identified as important contributors to mortality and hospital admissions, even when these end points are unrelated to PM mass. Sources may cause adverse health effects via their ability to produce reactive oxygen species in the body, possibly due to the transition metal content of the PM. Our goal is to quantify the oxidative potential of ambient particle sources collected during two seasons in Fresno, CA, using the dithiothreitol (DTT) assay. We collected PM from different sources or source combinations into different ChemVol (CV) samplers in real time using a novel source-oriented sampling technique based on singleparticle mass spectrometry. We segregated the particles from each source-oriented mixture into two size fractions - ultrafine $\left(D_{\mathrm{p}} \leq 0.17 \mu \mathrm{m}\right)$ and submicron fine $\left(0.17 \mu \mathrm{m} \leq D_{\mathrm{p}} \leq\right.$ $1.0 \mu \mathrm{m})-$ and measured metals and the rate of DTT loss in each PM extract. We find that the mass-normalized oxidative potential of different sources varies by up to a factor of 8 and that submicron fine PM typically has a larger massnormalized oxidative potential than ultrafine PM from the same source. Vehicular emissions, regional source mix, commute hours, daytime mixed layer, and nighttime inversion sources exhibit the highest mass-normalized oxidative potential. When we apportion DTT activity for total PM sampled to specific chemical compounds, soluble copper accounts for roughly $50 \%$ of total air-volume-normalized oxidative potential, soluble manganese accounts for $20 \%$, and other un-
\end{abstract}

known species, likely including quinones and other organics, account for $30 \%$. During nighttime, soluble copper and manganese largely explain the oxidative potential of PM, while daytime has a larger contribution from unknown (likely organic) species.

\section{Introduction}

Inhalation of particulate matter (PM) has been linked with adverse health effects and mortality in humans (Dominici et al., 2006; Dockery et al., 1993; Pope et al., 2002; Sunyer and Basagana, 2001; Breysse et al., 2013). Current regulations to protect health are based on PM mass without regard to source or chemical composition. While PM mass often exhibits good correlations with toxicity (Brunekreef and Holgate, 2002), the toxicity of PM is likely more complicated than mass alone, and may be defined by a combination of properties including number concentration, size, surface area, and chemical composition (Valavanidis et al., 2008; Adamson et al., 1999; Costa and Dreher, 1997; Stoeger et al., 2006; Peters et al., 1997; Perrone et al., 2013). These properties determine where PM will deposit in the lungs, how it will interact with the body, and how much oxidative stress it will produce (Churg and Brauer, 1997; Aust et al., 2002; Oberdorster et al., 2005; Yang et al., 2009). Oxidative stress is hypothesized as a primary mechanism for adverse health effects from PM (Ercan et al., 2006; Fearon and Faux, 2009; Halliwell and Cross, 1994), and occurs when reactive oxygen species (ROS) or other oxidants overwhelm the natural 
defenses of the body ( $\mathrm{Li}$ et al., 2003a). The picture is further complicated by the fact that PM is a complex mixture of particles from various primary and secondary sources with different degrees of atmospheric processing. Aging changes both the size distribution and chemical composition of PM (Ellison et al., 1999; Maring et al., 2003; Pirrone et al., 2000; Sullivan et al., 2007), making sources harder to differentiate and potentially changing the toxicity of the aerosol over time.

Recent epidemiological studies have identified specific sources or chemical components of PM that are associated with health outcomes even when PM mass is not, supporting the hypothesis that specific chemicals or sources have higher toxicities. These results indicate that PM mass may underestimate the extent of health effects from PM (Ito et al., 2011; Lall et al., 2011). Ostro et al. (2007) identified that mortality from PM in California was strongly tied to particulate $\mathrm{Cu}$ and other compounds, while Lall et al. (2011) identified steel and traffic PM in New York as sources associated with respiratory and cardiovascular hospital emissions, respectively. Traffic and residual oil fly ash are two sources commonly associated with adverse effects (Hoffmann et al., 2007; Peters et al., 2004; Dreher et al., 1997), possibly due to the ability of transition metals in the PM to cause oxidative stress (Gasser et al., 2009; Antonini et al., 2004; Aust et al., 2002; Dye et al., 1997; Costa and Dreher, 1997).

One of the primary tools used to identify sources of ambient PM is positive matrix factorization (PMF). PMF can be used in conjunction with in vitro (Zhang et al., 2008) or epidemiological (Lall et al., 2011) data to identify sources that are potentially important for human health. PMF was also recently applied to DTT data for particles collected in the southeastern USA (Verma et al., 2014). However, PMF requires intensive sampling and chemical analysis to obtain enough data for accurate source identification, which limits its applicability. In this work we use a novel method (Bein et al., 2009) to identify, separate, and collect ambient particles from different sources in real time based on their chemical composition. The method uses single-particle mass spectrometry coupled to a suite of particle samplers, which allows for source identification and collection on relatively short (min) timescales. Each source-oriented mixture of particles is collected on individual substrates as ultrafine (UF, $D_{\mathrm{p}} \leq$ $0.17 \mu \mathrm{m})$ and submicron fine (SMF, $0.17 \mu \mathrm{m} \leq D_{\mathrm{p}} \leq 1.0 \mu \mathrm{m}$ ) size fractions.

Using this technique we collected up to 10 sources over two sampling campaigns during 2008 and 2009 in Fresno, CA. In this paper we describe the soluble and total metal composition of the PM sources and their oxidative potential as measured by the dithiothreitol (DTT) assay. It should be noted that the DTT assay is insensitive to ROS production from iron (Fe) (Charrier and Anastasio, 2012; Lin and $\mathrm{Yu}, 2011)$, though Fe effectively produces the hydroxyl radical $\left({ }^{\circ} \mathrm{OH}\right)$ in particle extracts via the Fenton reaction (Vidrio et al., 2009). Thus, use of the DTT assay may underestimate oxidative potential from sources that are high in Fe. In our companion manuscript (part 2), we quantitatively measure the rate of production of ${ }^{\circ} \mathrm{OH}$ and hydrogen peroxide $(\mathrm{HOOH})$, from the same Fresno particles in a cell-free surrogate lung fluid, and compare these results with our DTT outcomes (Richards-Henderson et al., 2015). In this current paper, we examine differences in soluble metal composition and oxidative potential for different source-oriented particles collected in Fresno. We also quantify the contributions of different chemical species and particle sources to the measured oxidative potential as a function of season and particle size.

\section{Methods}

\subsection{Source-oriented particulate matter}

Source-oriented particles (i.e., particles primarily from one source or a mixture of a few sources) were identified and collected using online single-particle mass spectrometry (RSMS-II) as described in Bein et al. (2009). Downstream of the RSMS-II was a bank of 10 ChemVol (CV) samplers which are high-flow-rate $\left(900 \mathrm{~L} \mathrm{~min}^{-1}\right)$ impactor-based samplers (Demokritou et al., 2002) - for PM collection, with each CV assigned to one source or source combination. Table 1 lists the CVs for each collection season, with corresponding source identification and sampling information. Prior to sample collection, Bein et al. (2009) used a prestudy analysis in Fresno, CA, to determine up to eight major nighttime sources based on RSMS-II single-particle mass spectra, diurnal trends, and back trajectory analysis. These pre-study data were used to define the combination of spectra that identify a specific source. During later sample collection, when the single-particle mass spectrometer observed these spectra, sampling algorithms automatically switched the flow of ambient aerosol to the appropriate CV. We continuously collected PM over each sampling period, alternating between CVs as an individual source became dominant during nighttime sampling. If the RSMS-II identified a mixture of sources or an unidentified source, the flow was directed to the "nighttime inversion (CV 10)" sampler, which therefore represents a mixture of many different particle origins and histories. Daytime PM was not separated into sources because the lower PM mass and greater turbulent mixing in the boundary layer during the day did not allow for a clear separation of sources (Bein et al., 2009). Daytime PM were segregated into one to three samples based on time of day instead of chemical composition. These samples include "daytime mixed layer (CV 9)" for both seasons, along with "morning commute (CV 8)" and "evening commute (CV 7)" during winter 2009 (specific sampling times listed in Table 1). These sampling adjustments were made in winter 2009 based on sampling experience gained during summer 2008. "Evening commute (CV 7)" was only collected for the last five days of the winter 2009 study. 
Table 1. CV sample characteristics ${ }^{\mathrm{a}}$.

\begin{tabular}{|c|c|c|c|c|c|c|c|}
\hline Sample time & $\mathrm{CV}$ & Source & $\begin{array}{r}\% \text { of total } \\
\text { volume }\end{array}$ & $\begin{array}{l}\% \text { of total } \\
\text { UF mass }\end{array}$ & $\begin{array}{l}\% \text { of total } \\
\text { SMF mass }\end{array}$ & $\begin{array}{r}\text { UF mass } \\
\text { concentration } \\
\left(\mu \mathrm{g} \mathrm{m}^{-3}\right)\end{array}$ & $\begin{array}{r}\text { SMF mass } \\
\text { concentration } \\
\left(\mu \mathrm{g} \mathrm{m}^{-3}\right)\end{array}$ \\
\hline \multicolumn{8}{|l|}{ Summer 2008} \\
\hline & 1 & Cooking - NE & 11 & 13 & 11 & 3.0 & 7.8 \\
\hline & 2 & Secondary & 8 & 11 & 13 & 3.5 & 11.9 \\
\hline Night-source & 3 & Diesel-enriched & 0.3 & 0.4 & 0.4 & 3.0 & 9.3 \\
\hline segregated & 4 & Regional source mix & 0.3 & 0.4 & 0.3 & 3.4 & 9.0 \\
\hline samples & 5 & Vehicular emissions & 0.07 & 0.1 & 0.1 & 3.6 & 7.6 \\
\hline \multirow[t]{3}{*}{$15: 00-11: 00$} & 6 & Unknown - metals & 0.8 & 1.0 & 0.9 & 3.5 & 9.2 \\
\hline & 7 & Cooking - W & 0.2 & 0.1 & 0.1 & 2.0 & 5.1 \\
\hline & 10 & Nighttime inversion & 61 & 58 & 60 & 2.5 & 7.8 \\
\hline \multirow[t]{2}{*}{ Day 11:00-15:00 } & 9 & Daytime mixed layer & 18 & 16 & 14 & 2.3 & 6.2 \\
\hline & & Summer total ${ }^{\text {b: }}$ & $41568 \mathrm{~m}^{3}$ & $108 \mathrm{mg}$ & $327 \mathrm{mg}$ & 2.6 & 7.9 \\
\hline \multicolumn{8}{|l|}{ Winter 2009} \\
\hline & 1 & Residential heating & 0.9 & 3.1 & 2.9 & 6.9 & 8.6 \\
\hline & 2 & Secondary & 0.8 & 1.5 & 2.8 & 4.0 & 9.2 \\
\hline Night-source & 3 & Vehicular emissions & 0.6 & 1.2 & 1.8 & 4.2 & 8.4 \\
\hline segregated & 4 & Processed biomass & 0.2 & 0.9 & 0.7 & 8.2 & 8.9 \\
\hline samples & 5 & Regional source mix & 0.6 & 1.6 & 1.5 & 5.2 & 6.5 \\
\hline \multirow[t]{2}{*}{ 20:00-06:00 } & 6 & Cooking - W & 0.3 & 1.0 & 1.1 & 8.2 & 11.5 \\
\hline & 10 & Nighttime inversion & 48 & 44 & 43 & 1.9 & 2.4 \\
\hline Day 06:00-09:00 & 8 & Morning commute & 12 & 13 & 14 & 2.3 & 3.1 \\
\hline Day 09:00-17:00 & 9 & Daytime mixed layer & 35 & 32 & 30 & 2.0 & 2.3 \\
\hline \multirow[t]{2}{*}{ Day 17:00-20:00 } & 7 & Evening commute & 1.2 & 1.3 & 1.7 & 2.3 & 4.0 \\
\hline & & Winter total ${ }^{\mathrm{b}}$ : & $40029 \mathrm{~m}^{3}$ & $84.5 \mathrm{mg}$ & $109 \mathrm{mg}$ & 2.1 & 2.7 \\
\hline
\end{tabular}

${ }^{a}$ Data from (Bein et al., 2009). ${ }^{b}$ Totals are the sum of all CVs. Total mass concentrations were calculated from the total PM mass divided by the total volume collected for all sources.

Particles were collected in Fresno, CA, from 11 September 2008 to 21 October 2008 and from 1 March 2009 to 6 April 2009. To maintain consistency with previous publications (Bein et al., 2009, 2014; Bein and Wexler, 2014; Carosino et al., 2015), these study periods are designated "summer" and "winter", respectively, which reflect the timing of the corresponding pre-studies for the single-particle mass spectrometer, though actual sample collections were in fall and spring. For each $\mathrm{CV}$, particles were collected separately as ultrafine (UF, $D_{\mathrm{p}} \leq 0.17 \mu \mathrm{m}$ ) and submicron fine (SMF, $\left.0.17<D_{\mathrm{p}} \leq 1.0 \mu \mathrm{m}\right)$ size fractions. SMF samples were collected on polyurethane foam (PUF, Fisher Scientific), and UF samples were collected on Teflon-coated glass-fiber filters (Pall TX-40, Fisher Scientific).

\subsection{PM extraction and sample preparation}

The PM extraction is described in detail in Bein and Wexler (2014). Briefly, PM collection substrates were extracted via sonication using a sequential series of solvents: Milli-Q (18.2 M $\Omega \mathrm{cm})$, dichloromethane (HPLC grade,
99.9\%, Acros), then hexane (Optima, HPLC grade, $95 \%$, Fisher). The water fraction was extracted in a separatory funnel with dichloromethane and then hexane to remove organics (especially semivolatiles). The remaining water fraction was lyophilized (freeze-dried, Labconco FreeZone ${ }^{\circledR}$ ) to remove water ice leaving solid PM behind. The four dichloromethane and hexane extracts were dried under nitrogen and the remaining solid from all extractions, including the water fraction, were combined. The solid was stored under vacuum in the freezer $\left(-20^{\circ} \mathrm{C}\right)$ in $10 \mathrm{~mL}$ serum bottles with $20 \mathrm{~mm}$ rubber split stoppers (Labconco) until reconstitution. To obtain a total extracted mass for each PM sample, the vacuum-sealed serum bottles were gravimetrically weighed before and after PM was added using an A\&D model HR-202i semi-micro analytical balance $( \pm 0.01 \mathrm{mg})$. This method extracts over $90 \%$ of PM from the filters, and retains bulk chemical composition better than traditional extraction techniques, especially with regard to organics (Bein and Wexler, 2014).

To divide each particle sample into smaller aliquots, we first reconstituted the material in methanol (Fisher, HPLC 
grade, $99.9 \%$ ), sonicated for $\sim 10 \mathrm{~min}$ in a bath sonicator (Branson model 8510, Bransonic ${ }^{\circledR}$ ), and split the suspension into $8 \mathrm{~mL}$ amber glass (Thermo Scientific) vials for DTT analysis. Methanol in each vial was evaporated and the resulting solids were stored in the dark at $-20{ }^{\circ} \mathrm{C}$ until the day of each experiment.

\subsection{Dithiothreitol assay}

Dithiothreitol (DTT) is commonly used to measure the oxidative potential of PM (Cho et al., 2005; Charrier and Anastasio, 2012). This method measures the rate of loss of $100 \mu \mathrm{M}$ DTT at $37^{\circ} \mathrm{C}$ upon incubation with PM. The magnitude of the rate of DTT loss is proportional to the oxidative potential of the PM. We used DTT analysis methods identical to Charrier and Anastasio (2012). We warm the PM sample of known mass (Table S2) for $2 \mathrm{~min}$ in a $7.0 \mathrm{~mL}$ amber glass vial. We start the reaction by adding $100 \mu \mathrm{M}$ DTT in $0.10 \mathrm{M}$ phosphate buffer $\left(77.8 \mathrm{mM} \mathrm{Na}_{2} \mathrm{H}_{2} \mathrm{PO}_{4}\right.$ and $22.2 \mathrm{mM}$ $\mathrm{KH}_{2} \mathrm{PO}_{4}, \mathrm{pH} 7.4$; Chelex-treated) and then measure the concentration of DTT over time to calculate the linear rate of DTT loss. Each experiment includes a solution blank and positive control $\left(0.50 \mu \mathrm{M} \mathrm{Cu}(\mathrm{II}) \mathrm{SO}_{4}\right)$ to ensure reproducibility from day to day: our average $( \pm 1 \sigma, n=25)$ blank is $0.19 \pm 0.05 \mu \mathrm{M}$ DTT $\min ^{-1}$ and our average blank-corrected positive control is $0.76 \pm 0.05 \mu \mathrm{MDTT} \mathrm{min}^{-1}$. The average solution-blank-corrected filter blank ( $\pm 1 \sigma, n=3$ each) was $0.23 \pm 0.018$ and $0.22 \pm 0.003 \mu \mathrm{MDTT} \mathrm{min}^{-1}$ for the SMF and UF samples. Each PM sample and filter blank is analyzed in triplicate. All sample rates are corrected by their daily solution blank and average filter blank (which was already solution-blank-corrected). The final DTT rate for a given size fraction of source-oriented mixture (i.e., $\mathrm{CV}$ ) is reported as a PM-mass-normalized rate (pmol DTT $\min ^{-1} \mu \mathrm{g}^{-1} \mathrm{PM}$ ) according to

Mass-normalized DTT rate $=$

Blank-corrected rate of loss (pmolDTT $\min ^{-1}$ ) PM mass added to the vial $(\mu \mathrm{g})$

We also calculate the air-volume-normalized rate for a given season and size fraction (pmolDTT $\mathrm{min}^{-1} \mathrm{~m}^{-3}$ of air sampled) according to

Air-volume-normalized DTT rate $=$

$\sum \frac{\left.\text { (Mass-normalized DTT rate } \mathrm{CV}_{i} \times \text { total mass } \mathrm{CV}_{i}(\mu \mathrm{g})\right)}{\text { Total air volume for that season }\left(\mathrm{m}^{3}\right)}$,

where the numerator term is summed over each sourceoriented mixture $i$ and the total air volume collected is $41568 \mathrm{~m}^{3}$ for summer and $40029 \mathrm{~m}^{3}$ for winter. The error of each sample includes the standard deviation of replicates $(n=2-3)$, the error of mass in the sample (Table S2 in the Supplement), and propagated error of the filter blank ( $n=3-$ $5)$.
As we discuss in Supplement Sect. S1, there is a complication in the DTT assay that has not been appreciated previously: the DTT response from PM is nonlinearly related to PM mass when $\mathrm{Cu}$ and $\mathrm{Mn}$ are significant contributors to the oxidative potential, a consequence of the nonlinear concentration-response curves for these metals (Charrier and Anastasio, 2012). Thus the mass-normalized oxidative potential (Eq. 1) will sometimes vary with PM mass added to the vial, which complicates comparison between samples and confounds the interpretation of DTT data. As we discuss in Sect. S1, we are in the process of developing and validating a method to normalize DTT data for the PM mass extracted. Application of this preliminary method to the Fresno samples in this current work had little effect on the DTT results (Figs. S2 and S3) because most of the extracts used a sample mass concentration near the value we suggest for normalization $\left(10 \mu \mathrm{g} \mathrm{mL}^{-1}\right)$; thus we did not adjust the DTT responses for these samples (Sect. S1). However, the nonlinearity of the DTT assay to $\mathrm{Cu}$ and $\mathrm{Mn}$, coupled with the important contribution of these metals to ambient DTT activity in at least some locations, indicates that each DTT study must examine this issue and, if needed, account for the nonlinear response of the DTT rate with PM mass. Otherwise, DTT results might be significantly skewed by the PM mass extracted (e.g., Fig. S3).

\subsection{Transition metal analysis}

Soluble metals were measured by extracting the PM solid in acid-washed PTFE containers containing $5.0 \mathrm{~mL}$ of a surrogate lung fluid (SLF). The SLF is composed of PBS $\left(114 \mathrm{mM} \mathrm{NaCl}\right.$ (A.C.S., Fisher), $2.2 \mathrm{mM} \mathrm{KH}_{2} \mathrm{PO}_{4}$ (A.C.S., $99 \%$, Fisher), and $7.8 \mathrm{mM} \mathrm{Na}_{2} \mathrm{HPO}_{4}$ (A.C.S., Fisher) at $\mathrm{pH}$ 7.4 that is Chelex-treated to remove transition metals; Charrier and Anastasio, 2012) and four antioxidants $(200 \mu \mathrm{M}$ ascorbic acid (99\%, Fluka), $300 \mu \mathrm{M}$ citric acid (99.7\%, Sigma Aldrich), $100 \mu \mathrm{M}$ glutathione (98\%, Sigma Aldrich), and $100 \mu \mathrm{M}$ uric acid (A.C.S., Sigma Aldrich)). After 1.5 or $24 \mathrm{~h}$ of incubation on a wrist-action shake table, $400 \mu \mathrm{L}$ of the PM extract was filtered $(0.22 \mu \mathrm{m}$, PTFE syringe filter, Tisch Scientific) into a $15 \mathrm{~mL}$ acid-washed polypropylene centrifuge vial (Fisher Scientific) containing $3.6 \mathrm{~mL}$ of $3 \%$ nitric acid (Optima, Fisher Scientific) and then refrigerated until analysis. Samples were analyzed for $\mathrm{Ba}, \mathrm{Cd}, \mathrm{Co}$, $\mathrm{Cr}, \mathrm{Cu}, \mathrm{Fe}, \mathrm{Mn}, \mathrm{Mo}, \mathrm{Ni}, \mathrm{Pb}, \mathrm{V}$, and $\mathrm{Zn}$ by ICP-MS (Agilent $7500 \mathrm{CE}$ ); further details of ICP-MS analysis along with total metal analysis are given in Sect. S3. Soluble metal concentrations were corrected for the metal concentration in the solution blank and the corresponding solution-blank-corrected field blank. Errors were calculated from the variance between replicates and the propagated error of the solution and field blanks.

Conditions of the DTT assay differ from the SLF conditions under which the PM was extracted for metal analysis, i.e., temperature and the presence of antioxidants. Since these 
factors may affect soluble metal concentrations in the extract, we compared metal content in separate SLF and DTT extracts for 12 samples. We found very good agreement between the two techniques, except that Fe was sometimes higher in the SLF than DTT assay (Sect. S2), possibly because SLF contains citrate, which solubilizes particulate Fe (Aust et al., 2002). Although our soluble Fe concentrations in SLF are likely upper-bound estimates of the amounts in the DTT assay, Fe is a relatively weak oxidant for DTT (Charrier and Anastasio, 2012) and is a negligible contributor to DTT loss in our Fresno source-oriented samples, as we describe later.

\section{Results and discussion}

\subsection{Sample characteristics}

Table 1 summarizes the sampling characteristics and source identifications for each CV. Detailed source identification information can be found in Bein et al. (2009, 2014). Briefly, sources were identified based on chemical composition measured by the single-particle mass spectrometer, the temporal pattern of the source, and wind roses indicating the direction of the source. In addition to the timed daytime CVs, seven other sources were identified in summer and six in winter. Two distinct cooking sources were identified: "cooking - NE (CV 1)" is from the northeast, characterized by a high K content, while "cooking - W (CV 6 or CV 7)" comes from the west and is characterized by $\mathrm{K}$ and mixed $\mathrm{Na} / \mathrm{K}$ particles. In summer the "unknown - metals (CV 6)" source is of unknown origin and was identified based on high concentrations of metals, especially $\mathrm{Zn}$ and $\mathrm{Pb}$ (Bein et al., 2014).

The volume and mass of the collected PM for each sample varies widely depending on how often a source was dominant. During most nights, no single dominant source was identified, and sampling was directed to "nighttime inversion (CV 10)", which accounts for 40-60\% of PM mass in each season (Table 1). The difference in the percent of total mass attributed to "nighttime inversion (CV 10)" between seasons is partially driven by different sampling times: nighttime sampling was $18 \mathrm{~h}$ per day during summer and $10 \mathrm{~h}$ per day during winter (Table 1). The total air volume and total UF mass concentration are similar between seasons, approximately $40000 \mathrm{~m}^{3}$ and $\sim 80-100 \mathrm{mg}$, respectively. In contrast, the total SMF mass collected is 3 times larger in summer than in winter. In summer, UF mass concentrations for the CVs are relatively similar $\left(2.0-3.6 \mu \mathrm{g} \mathrm{m}^{-3}\right)$, while there is more variability in mass concentrations for PM sources in the other seasons and sizes: 5.1-11.9 for SMF in summer, 1.9-8.2 for UF in winter, and $2.3-11.5 \mu \mathrm{g} \mathrm{m}^{-3}$ for SMF in winter (Table 1).

\subsection{Metal composition by $\mathrm{CV}$}

Figure 1 shows the soluble metal content for each source, season, and size fraction in units of microns of metal per gram of PM; total metals are in the Supplement Fig. S5. Ambient concentrations $\left(\mathrm{ng} \mathrm{m}^{-3}\right)$ of total and soluble metals are summarized by season and size fraction in Table S1. The median soluble metal concentrations are at or below median levels from other regions of the USA (Charrier and Anastasio, 2012). The general trend in relative abundance follows $\mathrm{Zn} \gg \mathrm{Ba} \sim \mathrm{Fe}>\mathrm{Cu} \sim \mathrm{Mn}>\mathrm{Ni}>\mathrm{Pb} \sim \mathrm{V} \sim \mathrm{Cr}>\mathrm{Cd} \sim \mathrm{Co}$. On average, $\mathrm{Zn}, \mathrm{Ba}, \mathrm{Fe}, \mathrm{Cu}$, and $\mathrm{Mn}$ account for 66, 11, 10, 5.6, and $3.0 \%$ by mass of the all measured soluble metals, respectively, while other metals each account for less than $3 \%$. In the total metal data, Fe is slightly more important, accounting for $20 \%$ of the total on average, while $\mathrm{Zn}$ still dominates with an average of $57 \%$ of the total. Total and soluble metals are generally well correlated $\left(R^{2}=0.4-0.8\right)$, likely due to high solubility (50-100\%) in our system (Figs. S3 and S4 in the Supplement). Fe is the exception, showing poor correlation between total and soluble measurements $\left(R^{2}=0.15\right)$ and much lower solubility (median solubility of $27 \%$ ). A large percent of each particulate metal is soluble, with an average of approximately $100 \%$ for all species besides Fe, which has an average solubility of $29 \%$. Metal solubility in ambient $\mathrm{PM}$ depends on a number of factors including $\mathrm{pH}$, ligands, particle size, morphology, and extraction technique. A large range of metal solubilities in ambient $P M$ have been reported (Connell et al., 2006). However, the percent of particulate $\mathrm{Fe}$ that is soluble is generally low in ambient PM, with reports ranging from < 1 to $6 \%$ solubility (Costa and Dreher, 1997; Upadhyay et al., 2011; Connell et al., 2006). The high metal solubilities in the source-oriented particles might be due to the extraction procedure used to remove PM from their substrates required a number of analytical steps which may have changed some properties of the PM; for example, sonication of particles may have preferentially removed soluble metals and left some fraction of insoluble metals on the filter.

In general, the soluble metal content in microns of metal per gram of PM is similar for the two size fractions of a given source. Notable exceptions are "diesel-enriched (CV 3)", "vehicular emissions (CV 5)", and "unknown - metals (CV 6)" in summer and "regional source mix (CV 5)" in winter, all of which have a higher concentration of metals in the SMF size fraction compared to the UF, especially for Fe, $\mathrm{Cu}$, and $\mathrm{Mn}$. The metal content of PM (Fig. 1) and the ambient concentration of metals (Table S1) are often higher in summer sampling. Because the sampling periods were actually spring and fall, we do not expected the mixing height to affect concentrations differently between these two seasons. It is possible that periodic rain during the winter sampling explains some of the reduction in ambient concentrations of both PM mass and metals. NOAA precipitation data indicate no rain during summer sampling and 5 days of rain during winter sampling (NOAA, 2014). 


\subsection{Mass-normalized oxidative potential}

We start by examining the rate of DTT loss for each source normalized by PM mass (Eq. 1), which is a measure of the intrinsic oxidative potential of each source. Figure 2 shows that, for a given source, the SMF particles are generally more reactive than the accompanying UF particles: for approximately half of the PM sources the SMF reactivity is a factor of 2 larger than that for the UF fraction. This higher reactivity of the submicron fine particles is in contrast to past results, where ultrafine particles (typically $D_{\mathrm{p}}<0.1 \mu \mathrm{m}$ ) are generally reported to be more reactive than $\mathrm{PM}_{2.5}$ (Li et al., 2003b; Cho et al., 2005; Ntziachristos et al., 2007; Hu et al., 2008). All of these past measurements of size-segregated DTT responses are for California's South Coast Air Basin, while our results are the first for the Central Valley of California. Thus this difference in the mass-normalized oxidative potential between SMF and UF particles might reflect differences in sampling site.

Across both seasons, we observe a range of DTT rates for both UF and SMF PM, with values of 11-60 and 2492 pmol DTT $\min ^{-1} \mu \mathrm{g}^{-1} \mathrm{PM}$, respectively; that is, the massnormalized oxidative potential of different sources varies by up to a factor of 5.5 for UF and 3.8 for SMF particles. Our mass-normalized rates of DTT loss are similar to those reported in the literature (restricted to those studies using the same DTT method), which range from 5.0 to 170 pmol DTT $\min ^{-1} \mu \mathrm{g}^{-1}$ PM (Verma et al., 2009, 2012; Ntziachristos et al., 2007; De Vizcaya-Ruiz et al., 2006).

We also calculated the overall oxidative potential for each size fraction in each of the two seasons. This metric sums the mass-normalized oxidative potential of each particle type, weighted by the mass of that PM collected:

Mass-weighted oxidative potential $=\sum\left(F_{i, k} \times \mathrm{DTT}_{i, k}\right)$,

where $i$ refers to season (summer or winter), $k$ refers to size fraction (UF or SMF), $F$ is the fraction of total mass collected (Table 1), and DTT is the mass-normalized oxidative potential (Fig. 2, bars). This metric is similar to Eq. (2), which calculates the DTT response of the total PM relative to air volume, but instead calculates the DTT response of the total PM relative to PM mass. If we consider each season across both size fractions (i.e., summing over $k$ in Eq. 3), the overall oxidative potentials for summer and winter $\mathrm{PM}_{1.0}$ are $71 \pm 9$ and $45 \pm 2$ pmol DTT min $^{-1} \mu \mathrm{g}^{-1} \mathrm{PM}$, respectively. Thus, the average mass-normalized oxidative potential of summer PM is $60 \%$ higher than that of winter for our study periods. Broken down by season and size fraction, the weighted averages are $79 \pm 12$ and $47 \pm 4 \mathrm{pmol}$ DTT $\min ^{-1} \mu \mathrm{g}^{-1} \mathrm{PM}$ for summer SMF and UF size fractions, respectively, and $49 \pm 3$ and $39 \pm 3$ pmolDTT $\min ^{-1} \mu \mathrm{g}^{-1}$ PM for winter SMF and UF, respectively; these values are plotted as lines in Fig. 2. Thus the overall oxidative potential of SMF PM is higher than UF in both seasons, by $68 \%$ in summer and $26 \%$ in
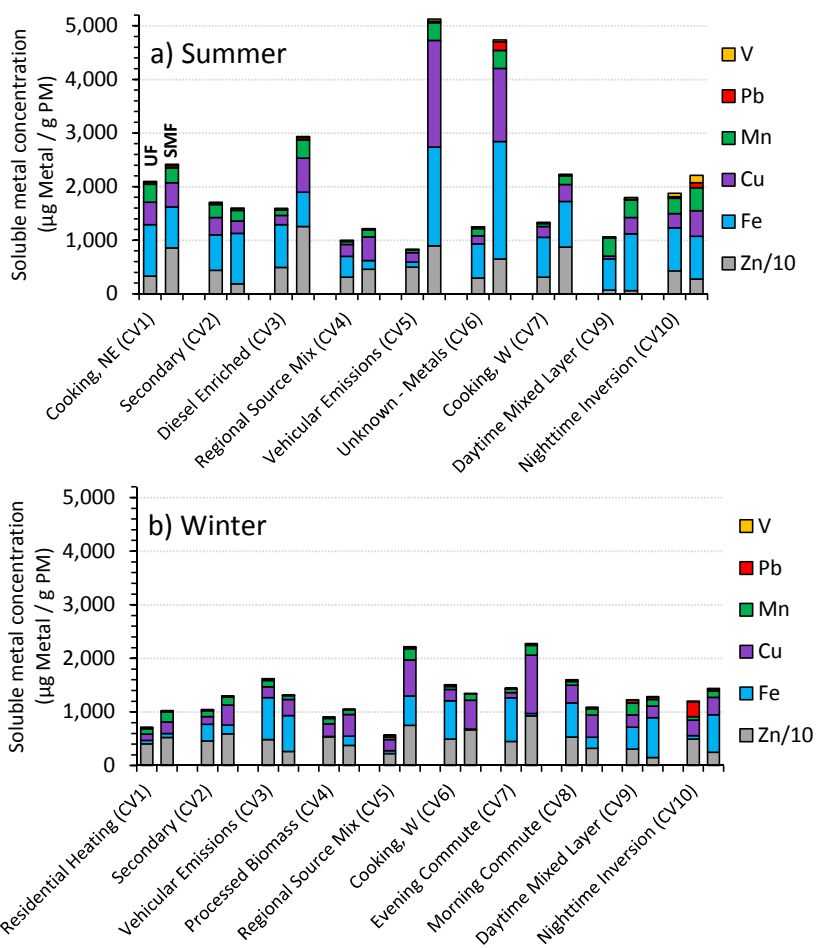

Figure 1. Soluble metal concentrations for (a) summer and (b) winter. For each $\mathrm{CV}$, the first bar is the result for the UF size fraction and the second bar is for the SMF size fraction. $\mathrm{Zn}$ concentrations are divided by 10 .

winter. Comparing the two seasons, the oxidative potential of summer SMF is $61 \%$ larger than winter SMF, while UF PM exhibited similar oxidative potential between the seasons. Based on these data, summer SMF PM stands out as having a substantially higher mass-normalized oxidative potential relative to the other PM.

When comparing each source-oriented mixture to the weighted average for season and size (bars versus lines in Fig. 2), most summer sources have an oxidative potential that is at or below the weighted average. This is because "nighttime inversion (CV 10)" accounts for most of the PM mass and has a high oxidative potential in summer for both UF and SMF PM, so it dominates the weighted average. In winter, there is less variability between the oxidative potentials of the different sources, but most sources are still at or below the weighted average defined by the "daytime mixed layer (CV 9)" and "nighttime inversion (CV 10)", which make up most of the PM mass. 


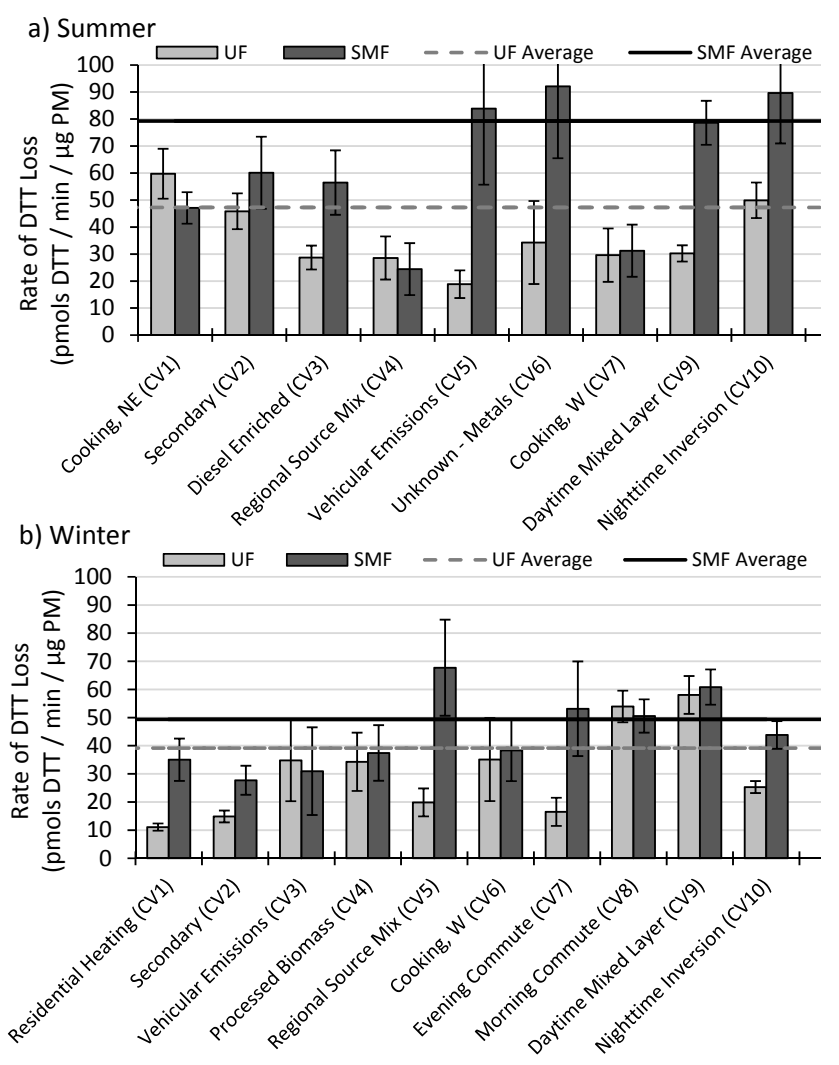

Figure 2. PM-mass-normalized rate of DTT loss for (a) summer and (b) winter. Lines represent the mass-weighted, average DTT loss over all CVs for UF (dashed line) and SMF (solid line) in a given season. Error bars are 1 standard deviation of replicates $(n=$ 2-3) with the propagated error of the filter blank.

\subsection{Contribution of transition metals to DTT activity}

DTT responses in Fig. 2 often mirror the soluble metal concentrations (Fig. 1), e.g., summer SMF "vehicular emissions (CV 5)" and "unknown - metals (CV 6)" have some of the highest DTT responses, and also have substantially higher soluble metal concentrations. Other sources, such as summer SMF "daytime mixed layer (CV 9)" and "nighttime inversion (CV 10)" also have a high DTT response but lower soluble metals per PM mass, indicating metals may not explain the DTT response in these cases. To quantify the contribution of each metal to our measured DTT response, we use our measured metal concentrations in each PM extract in conjunction with concentration-response curves for individual transition metals and quinones (Charrier and Anastasio, 2012). In this prior work we determined that the DTT responses from these individual species are additive: mixtures of metals and quinones give the same DTT response as the sum of the DTT responses from the individual species. Therefore, to calculate the total DTT response from soluble metals, we sum the calculated DTT response from each individual species.
Figure 3 shows the measured DTT rate (in grey) in each PM extract compared to the calculated DTT responses from $\mathrm{Cu}$ (purple), $\mathrm{Mn}$ (green), and $\mathrm{Fe}, \mathrm{V}$, and $\mathrm{Pb}$ (orange). If metals are primarily responsible for the DTT response, then the measured and calculated bars will be equal. If the measured DTT rate is larger than the calculated rate, it indicates that other compounds, such as quinones, contribute to DTT loss. In 36 out of the 38 samples, the measured and calculated rates of DTT loss are not statistically different ( $p<0.05$ ), highlighting the importance of copper and manganese. This agreement between measured and calculated DTT loss is sometimes due to large errors, which are primarily from uncertainties in the soluble metal measurements and in PM masses added to the vial (Table S2). However, visual inspection of most pairs shows good agreement. Although generally not statistically different, there are a number of cases where the measured DTT rate is larger than the DTT rate calculated from soluble metals. In these cases there is likely some contribution from other species, probably organic compounds, but the difference is encompassed by large error bars. Even in these samples metals generally account for half or more of the DTT, although there is a small but significant contribution from other species, as would be expected from typical ambient concentrations of quinones (as discussed below). There are also a few cases where the calculated DTT response is larger than the measured DTT response, but large error bars in the soluble metal data indicate these differences are generally due to experimental error. One exception is winter UF "nighttime inversion (CV 10)", which has a much larger calculated DTT response than we measured from PM. We do not currently have an explanation for this result, but it could be an outlier in either the DTT or soluble metal data.

On average $( \pm \sigma)$, soluble $\mathrm{Cu}$ and $\mathrm{Mn}$ account for $83 \pm 40$ and $26 \pm 14 \%$ of the measured DTT response, respectively, in our Fresno particles. $\mathrm{Fe}, \mathrm{V}$, and $\mathrm{Pb}$ each contribute less than $1 \%$ to DTT response; these contributions are too small to be seen for most samples in Fig. 3. These results represent the DTT response for the specific chemical composition of PM collected at this site. The DTT response from PM measured at other sites will depend on the composition of the particles and may not be dominated by transition metals. On the other hand, our interpretation of recent results from Atlanta and other sites in the southeastern USA also indicate $\mathrm{Cu}$ and $\mathrm{Mn}$ may play important roles in the DTT response (Verma et al., 2014; see reviewer's discussion at http://www.atmos-chem-phys-discuss.net/14/19625/ 2014/acpd-14-19625-2014-discussion.html). The DTT results for any site represent the specific chemical composition of the collected PM and the contributions to the resulting DTT response depend on the relative amounts of $\mathrm{Cu}, \mathrm{Mn}$, quinones, and other redox-active species.

Sources of $\mathrm{Cu}$ and $\mathrm{Mn}$ in Fresno are incompletely understood, as indicated by recent modeling that showed poor correlation between predicted and measured concentrations 

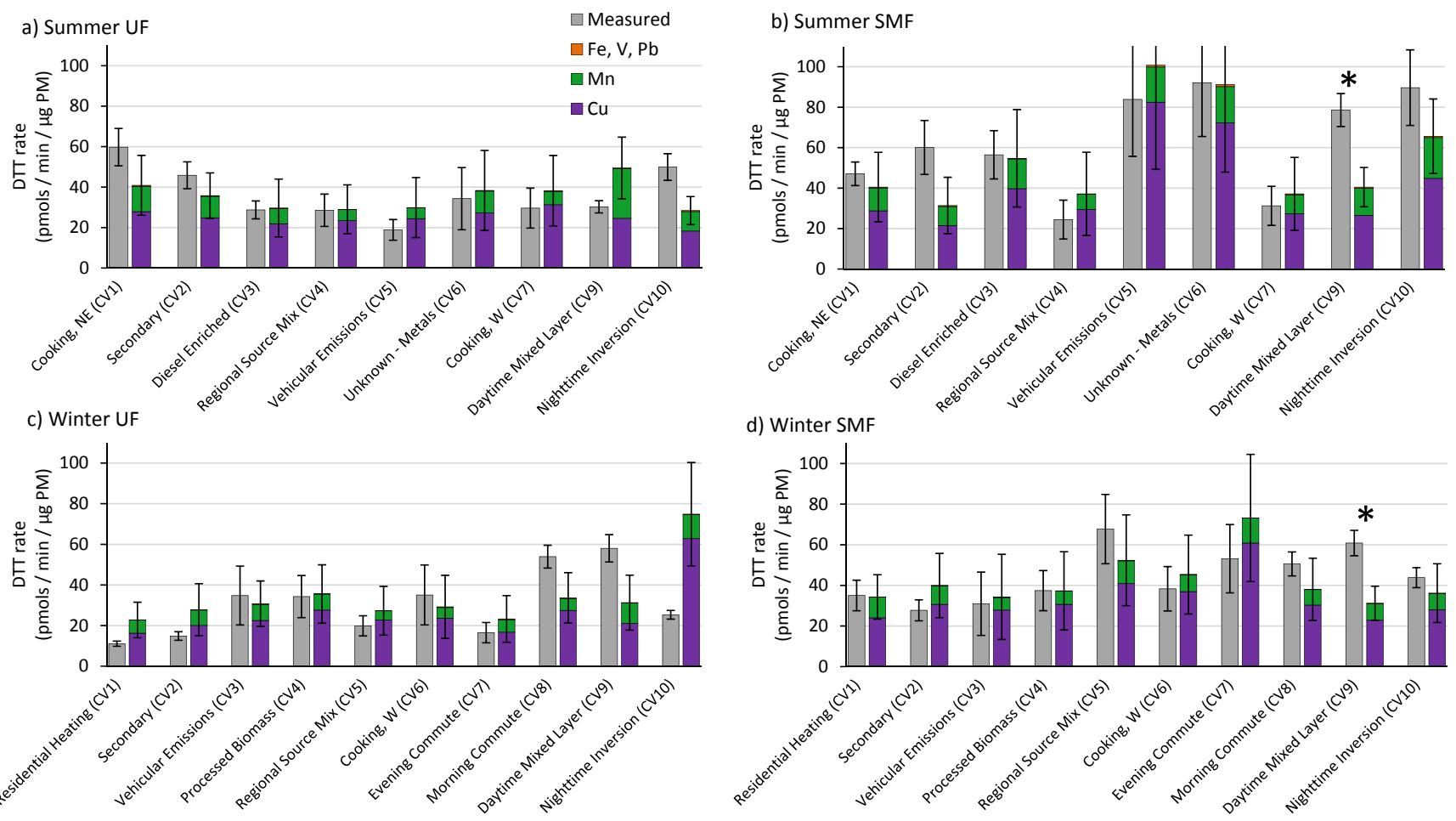

Figure 3. Measured rate of DTT loss (grey bars) compared to the calculated rate from soluble transition metals (colored stacked bars). Asterisks identify cases where the measured and calculated rates are statistically different $(p \leq 0.05)$. Errors for the calculated bars are \pm 1 standard deviation, propagated from the uncertainty in each of the five metals.

of $\mathrm{Cu}$ and $\mathrm{Mn}$ in $\mathrm{PM}_{2.5}$ and $\mathrm{PM}_{0.1}$ at Fresno (Hu et al., 2014). The model underpredicts $\mathrm{Cu}$ and overpredicts $\mathrm{Mn}$. In the USA, industrial $\mathrm{Cu}$ processing is thought to be the largest source of $\mathrm{Cu}$, followed by brake lining dust, agricultural soil, sintering furnaces, and process gas combustion, while Mn is primarily emitted by unpaved road dust, agricultural soil, electric arc furnaces, and cast iron cupola furnaces in foundries (Reff et al., 2009). Bukowiecki et al. (2009) observed $\mathrm{Cu}$ emissions from brake wear in the submicron range, especially from heavy duty vehicles. The relative importance of industrial sources will likely be smaller in California, while break lining dust and agricultural sources will likely be larger due to high vehicle miles traveled and intense agricultural activity. For example, some dairies use copper baths to treat cows for fungus and then pour the remaining solution into manure lagoons, which may then be spread to soils (Jokela et al., 2010).

The daytime samples summer SMF CV 9 and winter SMF and UF CV 8, as well as CV 9, stand out as having a relatively high contribution from unknown species (i.e., the measured rate of DTT loss is larger than the rate calculated from metals). The measured DTT response in both summer and winter SMF "daytime mixed layer (CV 9)" is statistically larger than calculated from transition metals (Fig. 3b and d, marked with stars). In both cases, unknown species account for $49 \%$ of the measured rates of DTT loss. This indicates that com- pounds other than the soluble metals we measured, likely quinones or other organics, sometimes make significant contributions to the PM oxidative potential. It is possible that insoluble metals also contribute to DTT loss by "unknown species", but this is less likely since the insoluble fraction of diesel PM (which has a low metal content) oxidizes DTT quickly, while insoluble dust (which has high metals) oxidizes DTT very slowly (Akhtar et al., 2010). Furthermore, based on our total and soluble metal data, most DTT-active metals (except Fe) have a high solubility (Fig. S7), while Fe is less soluble but has a very low DTT activity (Charrier and Anastasio, 2012). Hu et al. (2008) found a strong correlation between DTT response and organic carbon (OC) and observed that concentrations of OC are more than 4 times larger during the day than at night. This could explain our observed increase in DTT activity from compounds other than metals during the day. OC is made up of a wide variety of organic compounds, not all of which are DTT-active. Except for quinones (Kumagai et al., 2002; Charrier and Anastasio, 2012; Chung et al., 2006), it is largely unknown which organic compounds are active in the DTT assay. Recent research has identified humic-like substances (HULIS) as DTT-active (Verma et al., 2012; Lin and Yu, 2011), so these types of compounds may contribute to the oxidative potential of OC. 
We can estimate the likely contribution of quinones to our Fresno PM samples by using previously measured particulate concentrations of phenanthrenequinone (PQN), the most DTT-active quinone tested (Kumagai et al., 2002; Charrier and Anastasio, 2012; Chung et al., 2006). PQN has a median particulate-phase concentration of $0.32 \mathrm{ng}^{-1} \mathrm{~m}^{-3}$ based on (limited) measurements in southern California (Cho et al., 2004). If we assume this ambient concentration for all of our Fresno source-oriented mixtures (SMF + UF), and that all PQN is soluble, the resulting PQN concentration in solution is between 1 and $12 \mathrm{nM}$. This would correspond to DTT responses in the range of $0.01-0.16 \mu \mathrm{M}$ DTT $\min ^{-1}$, which represents $2-36 \%$ of the measured DTT rates (with an average $\pm 1 \sigma$ contribution of $13 \pm 9 \%$ ). This result agrees well with the observations in Fig. 3, which show a consistent but relatively small contribution of species besides $\mathrm{Cu}$ and $\mathrm{Mn}$ to measured DTT response. This is consistent with our previous calculations for $\mathrm{PM}_{2.5}$ based on typical literature concentrations of DTT-active species (Charrier and Anastasio, 2012), where $\mathrm{Cu}, \mathrm{Mn}$, and quinones accounted for 47, 28, and $18 \%$ of the calculated DTT response of a hypothetical "typical" fine particle sample. The specific organic species that contribute to DTT response are still incompletely understood, and may include species other than the PQN. These hypothetical results are a lower estimate for organic contribution to DTT response if other DTT-active organic species are present. It is also possible that PM samples underestimat the quinone contribution because semi-volatile organics might be lost during sampling or particle extraction, but we do not have any evidence for this.

In contrast to our mechanistic approach to identify the important DTT-active species in PM, previous studies generally use correlation analysis. However, correlations between our DTT results and measured soluble metal concentrations (Fig. S8a-c) reveal some of the difficulties with the correlation approach. $\mathrm{Cu}, \mathrm{Mn}$, and $\mathrm{Fe}$ are modestly correlated with DTT loss ( $R^{2}$ values of $0.40,0.56$, and 0.43 , respectively) and the correlation with $\mathrm{Cu}$ is the weakest, even though our mechanistic approach identifies $\mathrm{Cu}$ as the dominant contributor to DTT loss. The correlation understates the role of copper because this metal has a nonlinear concentrationresponse curve (see the green line in Supplement Fig. S8a). The positive correlation between DTT loss and Mn agrees with our mechanistic results, but the correlation with $\mathrm{Fe}$ is spurious (since Fe is nearly inactive in the DTT assay), and is possibly due to the covariance between Fe and Mn (Fig. S8f). These plots illustrate that correlation analysis is unlikely to identify the metals most important for DTT loss, which might explain the inconsistent correlations between DTT response and $\mathrm{Cu}$ in the literature (Ntziachristos et al., 2007; Hu et al., 2008).

\subsection{Air-volume-normalized oxidative potential}

While the mass-normalized oxidative potential in Figs. 2 and 3 is useful for identifying sources that have the highest potential for harm, the oxidative burden associated with an air parcel also depends on the particle mass concentration of each source. A source aerosol with a very high mass-normalized oxidative potential may not be important if its atmospheric mass concentration is low. As a first step to address this, we use Eq. (2) to calculate the air-volume-weighted DTT response for each size fraction and season. This metric weights both the intrinsic oxidative potential of a source and the relative abundance of that source. The volume-normalized oxidative potentials from both size fractions (i.e., all PM with $D_{\mathrm{p}} \leq 1.0 \mu \mathrm{m}$ ) for summer and winter are $746 \pm 90$ and $217 \pm 10$ pmol DTT $\min ^{-1} \mathrm{~m}^{-3}$ air, respectively. The DTT activity in the summer particles is over 3 times higher than in the winter because both the PM mass concentration and mass-normalized oxidative potential of that PM are higher in summer (Table 1 and Fig. 2), by factors of 2.2 and 1.6, respectively. The winter SMF and UF volume-normalized oxidative potentials are 135 and 83 molDTT $\min ^{-1} \mathrm{~m}^{-3}$ air, respectively, while the corresponding summer SMF and UF values are 623 and $123 \mathrm{pmolDTT} \mathrm{min}^{-1} \mathrm{~m}^{-3}$ air, respectively. SMF PM has a higher volume-normalized oxidative potential in both seasons, with summer SMF exhibiting very high oxidative potential due to high mass concentrations and high intrinsic oxidative potentials.

To identify which species and sources drive the airvolume-normalized responses, we next apportion the volume-normalized oxidative potential in two ways - by chemical composition and by source (Fig. 4). Figure $4 \mathrm{a}$ shows the contributions of soluble metals and unknown species for each size fraction and season as an absolute value, while Fig. 4b shows the data as a percent of the total DTT loss. Summer SMF particles have the greatest oxidative potential, approximately 6 times larger than the other conditions, and this response is due to $\mathrm{Cu}(47 \%)$, Mn $(21 \%)$, and unknown species (31\%). Even though the other conditions have much lower air-volume-normalized rates of DTT loss, the percent contributions from $\mathrm{Cu}, \mathrm{Mn}$, and unknowns are similar (Fig. 4b), although winter UF does not have a contribution from unknown species. Based on these results, unknown species, likely quinones or other organics, are important to the oxidative potential of PM in Fresno, but copper and manganese are the dominant redox-active species. The unknown contribution to PM is primarily from daytime sources (Fig. 3), consistent with secondary formation of quinones from PAHs (Eiguren-Fernandez et al., 2008; Wang et al., 2007). DTT response from most segregated nighttime sources, on the other hand, is completely explained by metals, with little unknown contribution (Fig. 3).

Apportionment of volume-normalized oxidative potential by source is more difficult because most $(>79 \%)$ of the mass collected either during times when sources were not 

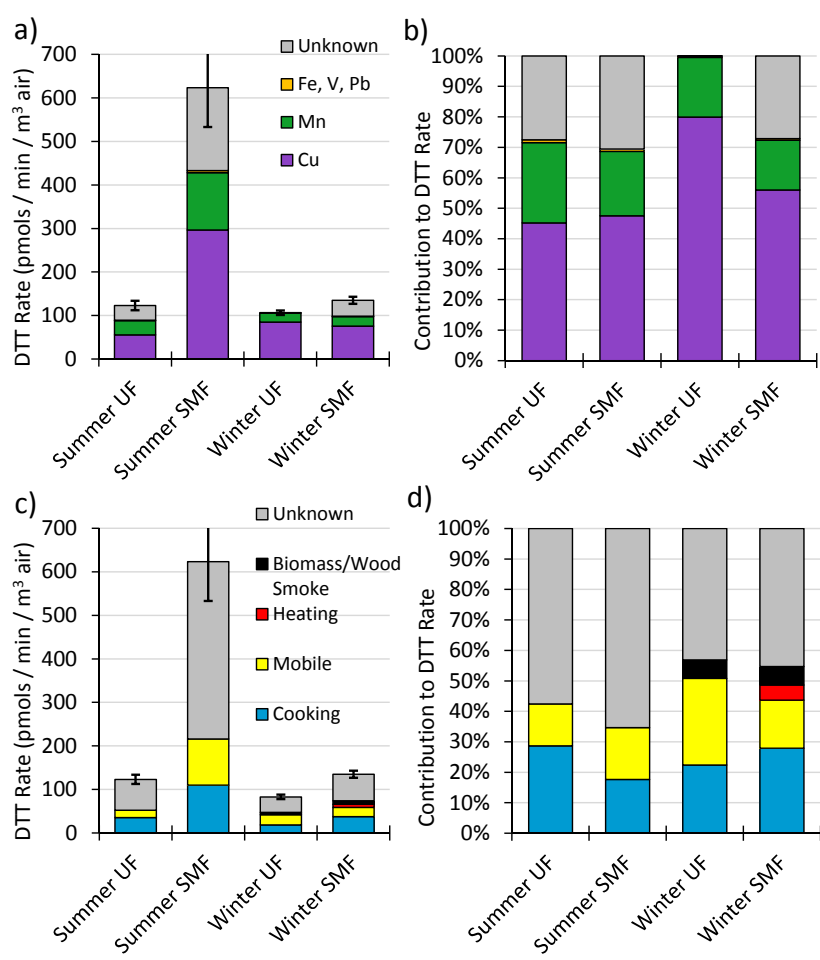

d)

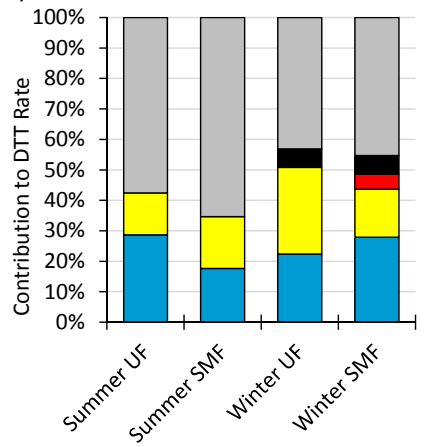

Figure 4. Panels (a) and (b) show the contributions of transition metals to the volume-normalized DTT loss for each season and size fraction, in terms of rates (a) and percent contribution (b). Panels (c) and (d) show the contributions of known (and unknown) particle emission sources to DTT loss, both in terms of rate (c) and percent contribution (d). "Unknown" in (a) and (b) indicates chemical species that contribute to DTT response besides measured metals. "Unknown" in (c) and (d) indicates unknown or other sources.

segregated (daytime) or as part of the catch-all "nighttime inversion (CV 10)" source. To more accurately quantify the prevalence of each source, we use modeling results for Fresno based on the California Air Resources Board's primary $\mathrm{PM}_{2.5}$ and $\mathrm{PM}_{0.1}$ emissions inventory (Hu et al., 2014). We match sources that we measured with emissions inventory sources, then use the modeling results that quantify the relative abundance of each emissions inventory source. There is additional uncertainty not explicitly accounted for due to the assumptions of matching our data to that in $\mathrm{Hu}$ et al. (2014), which are discussed in more detail in Sect. S6. The inventory in $\mathrm{Hu}$ et al. (2014) is the best available information of Fresno PM sources because it has been validated using ambient measurements, contains temporal information that allows matching to our specific measurement season, and is the only source of ultrafine PM source contributions available. A detailed summary of the source matching method is in the Supplement (Sect. S6 and Tables S3 and S4).

While there is significant uncertainty in our results, and major sources are unidentified or unknown, Fig. $4 \mathrm{c}$ and d show that cooking and mobile sources make important individual contributions, accounting for $18-29$ and $16-28 \%$, respectively, of the volume-normalized oxidative potential. Biomass/wood smoke was only identified during winter in our sampling, and contributes $6 \%$ to the volume-normalized oxidative potential for both the SMF and UF size fractions. Though our sample is designated as "winter", since we only caught the tail end of the wood burning season (Hu et al., 2014), these results contain relatively low ambient concentrations of wood burning and do not represent true winter conditions, when much more burning occurs. Heating was only identified during winter in the SMF size fraction, and contributes $5 \%$ to the volume-normalized oxidative potential. Unknown sources are significant, accounting for 43-45 of winter and $58-65 \%$ of summer volume-normalized oxidative potential. It is important to consider that this "unknown" result contains a combination of modeling and atmospheric PM mass that was either not identified as a specific source, did not match between the model and ambient sampling, or constituted a mixture of all identified sources. Additionally, modeling results used to identify the relative abundance of each source type use only primary PM mass, without accounting for the secondary mass present in our ambient samples. Thus, secondary organic aerosol (including reactions that produce quinones) are automatically included in the "unknown" category. In fact, most of the measured ambient $\mathrm{Cu}$ and $\mathrm{Mn}$ is apportioned to this category since most measured PM mass resides in this category. In summer, $76 \%$ of $\mathrm{Cu}$ and $83 \%$ of $\mathrm{Mn}$ are apportioned to this category, while in winter $77 \%$ of $\mathrm{Cu}$ and $90 \%$ of $\mathrm{Mn}$ are in the unknown categories. This is why it was necessary to use modeling results to properly apportion source contributions. These results also point out that the sources of $\mathrm{Cu}$ and $\mathrm{Mn}$ are poorly constrained in the current emissions inventory, especially in the "ultrafine" particles.

\subsection{Vehicular emissions}

Vehicular (mobile) emissions sources exhibited some of the highest mass-normalized oxidative potentials (Fig. 2), high soluble metal concentrations (Fig. 1), and a large contribution to total volume-normalized oxidative potential of PM (Fig. $4 \mathrm{c}$ and d). This agrees with literature results that have consistently linked vehicular emissions to both high oxidative potential (Cheung et al., 2010; Delfino et al., 2013; Gasser et al., 2009) and adverse health effects and mortality in humans (Lall et al., 2011; Hoek et al., 2002; Hoffmann et al., 2007). Vehicular emissions contain multiple toxic chemical classes across size ranges, including many metal and organic species. Metals can be emitted from brake wear, lubricating oil, and catalytic converters (Lough et al., 2005; Cheung et al., 2010; Zhao et al., 2006). Particulate organics from vehicles are both primary and secondary and are present across multiple size classes (Kam et al., 2012). Paved road dust is a large contribution to PM emissions in urban areas and consists of many sources of PM including soil, biogenic material, and tire and brake wear (Rogge et al., 1993). 
Though not directly emitted by vehicles, this source is correlated with vehicle traffic volume.

In our summer data, "vehicular emissions (CV 5)" showed high oxidative potential per mass of PM compared to other sources (Fig. 2a), and also high soluble metal concentrations (Fig. 1a). This source also showed significantly higher oxidative potential and soluble metals in the SMF size fraction versus UF, which is not true for a majority of other sources. Summer SMF "vehicular emissions (CV 5)" was enriched in soluble $\mathrm{Zn}, \mathrm{Fe}$, and $\mathrm{Cu}$, which were 46, 79, and $188 \%$ higher than the average summer SMF concentrations for the other sources, while concentrations of soluble $\mathrm{V}$ and $\mathrm{Mn}$ were similar to the average for the same size and season. $\mathrm{Zn}$ and $\mathrm{Cu}$ are known to be enriched in brake wear and road dust (Cheung et al., 2010), which have the largest concentrations in coarse sizes but also contribute to submicron PM (Kam et al., 2012). Thus the enhancement in soluble metals in the larger size fraction of summer Vehicular Emissions suggest brake wear or paved road dust can be important contributors to the oxidative potential of SMF vehicular emissions. Winter "vehicular emissions (CV 3)" did not exhibit the same pronounced enhancement in either soluble metals (Fig. 1b) or oxidative potential (Fig. 2b), nor did they show a difference between the two size fractions. We do not currently have a definitive explanation for this result; however, there was periodic rain during winter sampling which may have suppressed paved road dust.

\section{Conclusions}

We measured the oxidative potential of 38 source-oriented particle samples - separated into submicron fine (SMF) and ultrafine (UF) size fractions - from Fresno, CA, in summer 2008 and winter 2009 using the DTT assay. We also quantified total and soluble metals in each sample. Fe and $\mathrm{Zn}$ are the most abundant metals, followed by $\mathrm{Cu}$ and $\mathrm{Mn} . \mathrm{V}$ and $\mathrm{Pb}$ concentrations are extremely low, and $\mathrm{Co}, \mathrm{Cr}, \mathrm{Cd}$, and $\mathrm{Ni}$ are below detection. PM collected in summer 2008 has a higher metal content on average and an ambient SMF mass concentration 3 times higher. As a result, the oxidative potential of summer PM is $60 \%$ higher than winter PM per micron of particle mass. SMF samples generally show higher oxidative potentials on a mass-normalized basis compared to UF particles. Summer SMF sources with high oxidative potential include "vehicular emissions (CV 5)", "unknown - metals (CV 6)", "daytime mixed layer (CV 9)", and "nighttime inversion (CV 10)". UF sources with the highest oxidative potential per mass of PM include summer "cooking - NE (CV 1)", summer "nighttime inversion (CV 10)", winter "morning commute (CV 8)" and winter "daytime mixed layer (CV 9)". On an air-volume-normalized basis useful for considerations of human exposure, summer PM produces $240 \%$ more oxidative potential than winter PM per cubic meter of air. A total of $83 \%$ of summer oxidative potential is from the SMF size fraction.

Our results indicate that $\mathrm{Cu}$, and to a lesser extent $\mathrm{Mn}$, accounts for essentially all of the DTT response for most of our individual nighttime sources. DTT rates in the daytime sources are also generally dominated by metals, but these samples also have a large (up to $50 \%$ ) contribution from unknown compounds, likely quinones and other organics. When calculating the overall volume-normalized oxidative potential for each season (Fig. 4), $\mathrm{Cu}$ accounts for approximately $50 \%$, unknown species account for approximately $30 \%$, and $\mathrm{Mn}$ accounts for $20 \%$. These results are supported by recent epidemiological studies that found a statistical relationship between the $\mathrm{Cu}$ content of PM and mortality in California (Ostro et al., 2007). When we apportion our volume-normalized oxidative potential to sources, unknown/unconstrained sources make the largest contribution (43-65\%), while cooking accounts for 18-29\%, mobile sources account for 14-28\%, and heating and biomass combustion make minor contributions (though they will be larger in the winter months).

\section{The Supplement related to this article is available online at doi:10.5194/acp-15-2327-2015-supplement.}

Acknowledgements. We thank Joel Commisso at the UC Davis ICP-MS facility for soluble metal measurements, Tobias Kraft for assistance with data collection, Jianlin $\mathrm{Hu}$ and Mike Kleeman for useful discussions on air-volume-normalized DTT apportionment by source, and Shexia Ma for preliminary sample preparation. This research was made possible by Eladio Knipping and funding from EPRI (award \# P43512/C18871). Additional funding was provided through an EPA STAR graduate fellowship to J. G. Charrier (no. FP-91718101-0), by the National Institute of Environmental Health Sciences (grant \# P42ES004699), and by the California Agricultural Experiment Station (project CA-D-LAW-6403-RR). This work has not been formally reviewed by the EPA or NIEHS. The views expressed in this article are solely those of the authors and do not necessarily represent the views of the funders, who do not endorse any products or commercial services mentioned in this article.

Edited by: A. Huffman

\section{References}

Adamson, I. Y. R., Prieditis, H., and Vincent, R.: Pulmonary toxicity of an atmospheric particulate sample is due to the soluble fraction, Toxicology and Applied Pharmacology, 157, 43-50, 1999.

Akhtar, U. S., McWhinney, R. D., Rastogi, N., Abbatt, J. P. D., Evans, G. J., and Scott, J. A.: Cytotoxic and proinflammatory effects of ambient and source-related particulate matter (PM) in relation to the production of reactive oxygen species (ROS) and cytokine adsorption by particles, Inhal. Tox., 22, 37-47, 2010. 
Antonini, J. M., Taylor, M. D., Leonard, S. S., Lawryk, N. J., Shi, X. L., Clarke, R. W., and Roberts, J. R.: Metal composition and solubility determine lung toxicity induced by residual oil fly ash collected from different sites within a power plant, Mol. Cell. Biochem., ISI:000187068800028, 257-265, 2004.

Aust, A. E., Ball, J. C., Hu, A. A., Lighty, J. S., Smith, K. R., Straccia, A. M., Veranth, J. M., and Young, W. C.: Particle characteristics responsible for effects on human lung epithelial cells, Research report (Health Effects Institute), 110, 1, 2002.

Bein, K. J. and Wexler, A. S.: A high-efficiency, low-bias method for extracting particulate matter from filter and impactor substrates, Atmos. Environ., 90, 87-95, 2014.

Bein, K. J., Zhao, Y., and Wexler, A. S.: Conditional sampling for source-oriented toxicological studies using a single particle mass spectrometer, Environ. Sci. Technol., 43, 9445-9452, doi:10.1021/es901966a, 2009.

Bein, K. J., Zhao, Y., and Wexler, A. S.: Retrospective source attribution for source-oriented sampling and toxicity, Environ. Sci. Technol., submitted, 2014.

Breysse, P. N., Delfino, R. J., Dominici, F., Elder, A. C. P., Frampton, M. W., Froines, J. R., Geyh, A. S., Godleski, J. J., Gold, D. R., Hopke, P. K., Koutrakis, P., Li, N., Oberdorster, G., Pinkerton, K. E., Samet, J. M., Utell, M. J., and Wexler, A. S.: US EPA particulate matter research centers: summary of research results for 2005-2011, Air Quality, Atmosphere and Health, 6, 333-355, 2013.

Brunekreef, B. and Holgate, S. T.: Air pollution and health, Lancet, 360, 1233-1242, 2002.

Bukowiecki, N., Lienemann, P., Hill, M., Figi, R., Richard, A., Furger, M., Rickers, K., Falkenberg, G., Zhao, Y. J., Cliff, S. S., Prevot, A. S. H., Baltensperger, U., Buchmann, B., and Gehrig, R.: Real-world emission factors for antimony and other brake wear related trace elements: Size-segregated values for light and heavy duty vehicles, Environ. Sci. Technol., 43, 8072-8078, 2009.

Carosino, C. M., Bein, K. J., Plummer, L. E., Castaneda, A., Zhao, Y., Wexler, A. S., and Pinkerton, K. E.: Allergic Airway Inflammation is Differentially Exacerbated by Daytime and Nighttime Ultrafine and Submicron Fine Ambient Particles: Heme Oxygenase-1 as an Indicator of PM-Mediated Allergic Inflammation, J. Toxicol. Env. Health, Part A, 78, 254-266, doi:10.1080/15287394.2014.959627, 2015.

Charrier, J. G. and Anastasio, C.: On dithiothreitol (DTT) as a measure of oxidative potential for ambient particles: evidence for the importance of soluble transition metals, Atmos. Chem. Phys., 12, 9321-9333, doi:10.5194/acp-12-9321-2012, 2012.

Cheung, K. L., Ntziachristos, L., Tzamkiozis, T., Schauer, J. J., Samaras, Z., Moore, K. F., and Sioutas, C.: Emissions of Particulate Trace Elements, Metals and Organic Species from Gasoline, Diesel, and Biodiesel Passenger Vehicles and Their Relation to Oxidative Potential, Aerosol Sci. Technol., 44, 500-513, 2010.

Cho, A. K., Di Stefano, E., You, Y., Rodriguez, C. E., Schmitz, D. A., Kumagai, Y., Miguel, A. H., Eiguren-Fernandez, A., Kobayashi, T., Avol, E., and Froines, J. R.: Determination of four quinones in diesel exhaust particles, SRM 1649a, an atmospheric $\mathrm{PM}_{2.5}$, Aerosol Sci. Technol., 38, 68-81, 2004.

Cho, A. K., Sioutas, C., Miguel, A. H., Kumagai, Y., Schmitz, D. A., Singh, M., Eiguren-Fernandez, A., and Froines, J. R.: Redox activity of airborne particulate matter at different sites in the Los Angeles Basin, Environ. Res., 99, 40-47, 2005.

Chung, M. Y., Lazaro, R. A., Lim, D., Jackson, J., Lyon, J., Rendulic, D., and Hasson, A. S.: Aerosol-borne quinones and reactive oxygen species generation by particulate matter extracts, Environ. Sci. Technol., 40, 4880-4886, 2006.

Churg, A. and Brauer, M.: Human lung parenchyma retains $\mathrm{PM}_{2.5}$, Am. J. Respir. Crit. Care Med., 155, 2109-2111, 1997.

Connell, D. P., Winter, S. E., Conrad, V. B., Kim, M., and Crist, K. C.: The Steubenville Comprehensive Air Monitoring Program (SCAMP): Concentrations and solubilities of $\mathrm{PM}_{2.5}$ trace elements and their implications for source apportionment and health research, J. Air Waste Manage. Assoc., 56, 1750-1766, 2006.

Costa, D. L. and Dreher, K. L.: Bioavailable transition metals in particulate matter mediate cardiopulmonary injury in healthy and compromised animal models, Environ. Health Perspect., 105, 1053-1060, 1997.

De Vizcaya-Ruiz, A., Gutierrez-Castillo, M. E., Uribe-Ramirez, M., Cebrian, M. E., Mugica-Alvarez, V., Sepulveda, J., Rosas, I., Salinas, E., Garcia-Cuellar, C., Martinez, F., Alfaro-Moreno, E., Torres-Flores, V., Osornio-Vargas, A., Sioutas, C., Fine, P. M., Singh, M., Geller, M. D., Kuhn, T., Miguel, A. H., EigurenFernandez, A., Schiestl, R. H., Reliene, R., and Froines, J.: Characterization and in vitro biological effects of concentrated particulate matter from Mexico City, Atmos. Environ., 40, 583-592, 2006.

Delfino, R. J., Staimer, N., Tjoa, T., Gillen, D. L., Schauer, J. J., and Shafer, M. M.: Airway inflammation and oxidative potential of air pollutant particles in a pediatric asthma panel, J. Expo. Sci. Environ. Epidemiol., 23, 466-473, 2013.

Demokritou, P., Kavouras, I. G., Ferguson, S. T., and Koutrakis, P.: Development of a high volume cascade impactor for toxicological and chemical characterization studies, Aerosol Sci. Technol., 39, 925-933, 2002.

Dockery, D. W., Pope, C. A., Xu, X. P., Spengler, J. D., Ware, J. H., Fay, M. E., Ferris, B. G., and Speizer, F. E.: An association between air pollution and mortality in 6 United-States cities, N. Engl. J. Med., 329, 1753-1759, 1993.

Dominici, F., Peng, R. D., Bell, M. L., Pham, L., McDermott, A., Zeger, S. L., and Samet, J. M.: Fine particulate air pollution and hospital admission for cardiovascular and respiratory diseases, Jama-J. Am. Med. Assoc., 295, 1127-1134, 2006.

Dreher, K. L., Jaskot, R. H., Lehmann, J. R., Richards, J. H., McGee, J. K., Ghio, A. J., and Costa, D. L.: Soluble transition metals mediate residual oil fly ash induced acute lung injury, J. Toxicol. Env. Health, 50, 285-305, 1997.

Dye, J. A., Adler, K. B., Richards, J. H., and Dreher, K. L.: Epithelial injury induced by exposure to residual oil fly-ash particles: Role of reactive oxygen species?, Am. J. Respir. Cell Mol. Biol., 17, 625-633, 1997.

Eiguren-Fernandez, A., Miguel, A. H., Lu, R., Purvis, K., Grant, B., Mayo, P., Di Stefano, E., Cho, A., and Froines, J.: Atmospheric formation of 9,10-phenanthraquinone in the Los Angeles air basin, Atmos. Environ., 42, 2312-2319, 2008.

Ellison, G. B., Tuck, A. F., and Vaida, V.: Atmospheric processing of organic aerosols, J. Geophys. Res.-Atmos., 104, 11633$11641,1999$.

Ercan, H., Birben, E., Dizdar, E. A., Keskin, O., Karaaslan, C., Soyer, O. U., Dut, R., Sackesen, C., Besler, T., and Kalayci, O.: 
Oxidative stress and genetic and epidemiologic determinants of oxidant injury in childhood asthma, J. Allergy Clin. Immun., 118, 1097-1104, doi:10.1016/j.jaci.2006.08.012, 2006.

Fearon, I. M. and Faux, S. P.: Oxidative stress and cardiovascular disease: Novel tools give (free) radical insight, J. Mol. Cell. Cardiol., 47, 372-381, doi:10.1016/j.yjmcc.2009.05.013, 2009.

Gasser, M., Riediker, M., Mueller, L., Perrenoud, A., Blank, F., Gehr, P., and Rothen-Rutishauser, B.: Toxic effects of brake wear particles on epithelial lung cells in vitro, Part. Fibre Toxicol., 6, 30 doi:10.1186/1743-8977-6-30, 2009.

Halliwell, B. and Cross, C. E.: Oxygen-derived species - their relation to human-disease and environmental stress, Environ. Health Perspect., 102, 5-12, 1994.

Hoek, G., Brunekreef, B., Goldbohm, S., Fischer, P., and van den Brandt, P. A.: Association between mortality and indicators of traffic-related air pollution in the Netherlands: a cohort study, Lancet, 360, 1203-1209, 2002.

Hoffmann, B., Moebus, S., Mohlenkamp, S., Stang, A., Lehmann, N., Dragano, N., Schmermund, A., Memmesheimer, M., Mann, K., Erbel, R., and Jockel, K. H.: Residential exposure to traffic is associated with coronary atherosclerosis, Circulation, 116, 489496, 2007.

Hu, J., Hongliang, Z., Chen, S., Ying, Q., Wiedinmyer, C., Vandenberghe, F., and Kleeman, M.: Identifying $\mathrm{PM}_{2.5}$ and $\mathrm{PM}_{0.1}$ sources for epidemological studies in California, Environ. Sci. Technol., 48, 4980-4990, 2014.

Hu, S., Polidori, A., Arhami, M., Shafer, M. M., Schauer, J. J., Cho, A., and Sioutas, C.: Redox activity and chemical speciation of size fractioned PM in the communities of the Los Angeles-Long Beach harbor, Atmos. Chem. Phys., 8, 64396451, doi:10.5194/acp-8-6439-2008, 2008.

Ito, K., Mathes, R., Ross, Z., Nadas, A., Thurston, G., and Matte, T.: Fine particulate matter constituents associated with cardiovascular hospitalizations and mortality in New York City, Environ. Health Perspect., 119, 467-473, 2011.

Jokela, W. E., Tilley, J. P., and Ross, D. S.: Manure nutrient content on Vermont dairy farms: long-term trends and relationships, Commun. Soil Sci. Plant, 41, 623-637, 2010.

Kam, W., Liacos, J. W., Schauer, J. J., Delfino, R. J., and Sioutas, C.: Size-segregated composition of particulate matter (PM) in major roadways and surface streets, Atmos. Environ., 55, 90-97, 2012.

Kumagai, Y., Koide, S., Taguchi, K., Endo, A., Nakai, Y., Yoshikawa, T., and Shimojo, N.: Oxidation of proximal protein sulfhydryls by phenanthraquinone, a component of diesel exhaust particles, Chem. Res. Tox., 15, 483-489, doi:10.1021/tx0100993, 2002.

Lall, R., Ito, K., and Thurston, G.: Distributed lag analyses of daily hospital admissions and source-apportioned fine particle air pollution, Environ. Health Perspect., 119, 455-460, 2011.

Li, N., Hao, M. Q., Phalen, R. F., Hinds, W. C., and Nel, A. E.: Particulate air pollutants and asthma - A paradigm for the role of oxidative stress in PM-induced adverse health effects, $\mathrm{Cl}$. Immun., 109, 250-265, doi:10.1016/j.clim.2003.08.006, 2003a.

Li, N., Sioutas, C., Cho, A., Schmitz, D., Misra, C., Sempf, J., Wang, M. Y., Oberley, T., Froines, J., and Nel, A.: Ultrafine particulate pollutants induce oxidative stress and mitochondrial damage, Environ. Health Perspect., 111, 455-460, 2003b.
Lin, P. and Yu, J. Z.: Generation of reactive oxygen species mediated by humic-like substances in atmospheric aerosols, Environ. Sci. Technol., 45, 10362-10368, 2011.

Lough, G. C., Schauer, J. J., Park, J. S., Shafer, M. M., Deminter, J. T., and Weinstein, J. P.: Emissions of metals associated with motor vehicle roadways, Environ. Sci. Technol., 39, 826-836, 2005.

Maring, H., Savoie, D. L., Izaguirre, M. A., Custals, L., and Reid, J. S.: Mineral dust aerosol size distribution change during atmospheric transport, J. Geophys. Res.-Atmos., 108, 2156-2202, doi:10.1029/2002JD002536, 2003.

NOAA: Climate Data Online, available at:http://www.ncdc.noaa. gov/cdo-web/ (last access: 21 November 2014), 2014.

Ntziachristos, L., Froines, J. R., Cho, A. K., and Sioutas, C.: Relationship between redox activity and chemical speciation of size-fractionated particulate matter, Part. Fibre Toxicol., 4, 5, doi:10.1186/1743-8977-4-5, 2007.

Oberdorster, G., Oberdorster, E., and Oberdorster, J.: Nanotoxicology: An emerging discipline evolving from studies of ultrafine particles, Environ. Health Perspect., 113, 823-839, 2005.

Ostro, B., Feng, W.-Y., Broadwin, R., Green, S., and Lipsett, M.: The effects of components of fine particulate air pollution on mortality in California: Results from CALFINE, Environ. Health Perspect., 115, 13-19, 2007.

Perrone, M. G., Gualtieri, M., Consonni, V., Ferrero, L., Sangiorgi, G., Longhin, E., Ballabio, D., Bolzacchini, E., and Camatini, M.: Particle size, chemical composition, seasons of the year and urban, rural or remote site origins as determinants of biological effects of particulate matter on pulmonary cells, Environ. Pollut., 176, 215-227, 2013.

Peters, A., Wichmann, H. E., Tuch, T., Heinrich, J., and Heyder, J.: Respiratory effects are associated with the number of ultrafine particles, Am. J. Respir. Crit. Care Med., 155, 1376-1383, 1997.

Peters, A., von Klot, S., Heier, M., Trentinaglia, I., Hormann, A., Wichmann, H. E., and Lowel, H.: Exposure to traffic and the onset of myocardial infarction, N. Engl. J. Med., 351, 1721-1730, 2004.

Pirrone, N., Hedgecock, I. M., and Forlano, L.: Role of the ambient aerosol in the atmospheric processing of semivolatile contaminants: A parameterized numerical model (Gas-Particle Partitioning (GASPAR)), J. Geophys. Res.-Atmos., 105, 9773-9790, 2000.

Pope, C. A., Burnett, R. T., Thun, M. J., Calle, E. E., Krewski, D., Ito, K., and Thurston, G. D.: Lung cancer, cardiopulmonary mortality, and long-term exposure to fine particulate air pollution, Jama, 287, 1132-1141, 2002.

Reff, A., Bhave, P. V., Simon, H., Pace, T. G., Pouliot, G. A., Mobley, J. D., and Houyoux, M.: Emissions Inventory of PM2.5 Trace Elements across the United States, Environ. Sci. Technol., 43, 5790-5796, 2009.

Richards-Henderson, N. K., Charrier, J. G., Bein, K. J., Bau, D., Wexler, A. S., and Anastasio, C.: Oxidant production from source-oriented particulate matter - Part 2: Hydrogen peroxide and hydroxyl radical, Atmos. Chem. Phys., in preparation, 2015.

Rogge, W. F., Hildemann, L. M., Mazurek, M. A., Cass, G. R., and Simoneit, B. R. T.: Sources of fine organic aerosol .3. Road dust, tire debris, and organometallic brake lining dust - roads as sources and sinks, Environ. Sci. Technol., 27, 1892-1904, 1993. 
Stoeger, T., Reinhard, C., Takenaka, S., Schroeppel, A., Karg, E., Ritter, B., Heyder, J., and Schulz, H.: Instillation of six different ultrafine carbon particles indicates a surface area threshold dose for acute lung inflammation in mice, Environ. Health Perspect., 114, 328-333, 2006

Sullivan, R. C., Guazzotti, S. A., Sodeman, D. A., and Prather, K. A.: Direct observations of the atmospheric processing of Asian mineral dust, Atmos. Chem. Phys., 7, 1213-1236, doi:10.5194/acp-7-1213-2007, 2007.

Sunyer, J. and Basagana, X.: Particles, and not gases, are associated with the risk of death in patients with chronic obstructive pulmonary disease, Int. J. Epidemiol., 30, 1138-1140, 2001.

Upadhyay, N., Majestic, B. J., and Herckes, P.: Solubility and speciation of atmospheric iron in buffer systems simulating cloud conditions, Atmos. Environ., 45, 1858-1866, doi:10.1016/j.atmosenv.2011.01.010, 2011.

Valavanidis, A., Fiotakis, K., and Vlachogianni, T.: Airborne Particulate Matter and Human Health: Toxicological Assessment and Importance of Size and Composition of Particles for Oxidative Damage and Carcinogenic Mechanisms, J. Environ. Sci. Health Pt. C-Environ. Carcinog. Ecotoxicol. Rev., 26, 339-362, 2008.

Verma, V., Polidori, A., Schauer, J. J., Shafer, M. M., Cassee, F. R., and Sioutas, C.: Physicochemical and toxicological profiles of particulate matter in Los Angeles during the October 2007 Southern California wildfires, Environ. Sci. Technol., 43, 954960, 2009.

Verma, V., Rico-Martinez, R., Kotra, N., King, L., Liu, J. M., Snell, T. W., and Weber, R. J.: Contribution of Water-Soluble and Insoluble Components and Their Hydrophobic/Hydrophilic Subfractions to the Reactive Oxygen Species-Generating Potential of Fine Ambient Aerosols, Environ. Sci. Technol., 46, 1138411392, 2012.
Verma, V., Fang, T., Guo, H., King, L., Bates, J. T., Peltier, R. E., Edgerton, E., Russell, A. G., and Weber, R. J.: Reactive oxygen species associated with water-soluble $\mathrm{PM}_{2.5}$ in the southeastern United States: spatiotemporal trends and source apportionment, Atmos. Chem. Phys., 14, 12915-12930, doi:10.5194/acp14-12915-2014, 2014.

Vidrio, E., Phuah, C. H., Dillner, A. M., and Anastasio, C.: Generation of hydroxyl radicals from ambient fine particles in a surrogate lung fluid solution, Environ. Sci. Technol., 43, 922-927, doi:10.1021/es801653u, 2009.

Wang, L., Atkinson, R., and Arey, J.: Formation of 9,10phenanthrenequinone by atmospheric gas-phase reactions of phenanthrene, Atmos. Environ., 41, 2025-2035, 2007.

Yang, H., Liu, C., Yang, D. F., Zhang, H. S., and Xi, Z. G.: Comparative study of cytotoxicity, oxidative stress and genotoxicity induced by four typical nanomaterials: the role of particle size, shape and composition, J. Appl. Toxicol., 29, 69-78, 2009.

Zhang, Y. X., Schauer, J. J., Shafer, M. M., Hannigan, M. P., and Dutton, S. J.: Source apportionment of in vitro reactive oxygen species bioassay activity from atmospheric particulate matter, Environ. Sci. Technol., 42, 7502-7509, doi:10.1021/es800126y, 2008.

Zhao, P. S., Feng, Y. C., Zhu, T., and Wu, J. H.: Characterizations of resuspended dust in six cities of North China, Atmos. Environ., 40, 5807-5814, 2006. 